\title{
Serum osteocalcin levels in postmenopausal osteoporotic women receiving alendronate
}

\author{
Mohsen Soroosh ${ }^{1}$, Alireza Khabbazi ${ }^{2}$, Aida Malek Mahdavi ${ }^{2 *}$ \\ ${ }^{1}$ Rheumatology Section, Department of Internal Medicine, AJA University of Medical Sciences, Tehran, Iran; ${ }^{2}$ Connective Tissue \\ Diseases Research Center, Tabriz University of Medical Sciences, Tabriz, Iran
}

\begin{abstract}
Osteoporosis is characterized by low bone mass, changes in the microscopic structure of bone, and increased bone fragility. Monitoring response to treatment is critical for the appropriate management of osteoporosis. Serum osteocalcin has become known as a bone formation biomarker for the evaluation of treatment response in postmenopausal osteoporosis. The present study assessed the effect of alendronate on serum osteocalcin levels in patients with postmenopausal osteoporosis. Thirty-four women with postmenopausal osteoporosis diagnosed by DEXA received alendronate $10 \mathrm{mg} /$ day for 3 months. Serum osteocalcin, calcium, phosphorus, and alkaline phosphatase (ALP) were measured at baseline and after 45 and 90 days. Mean age and duration of menopause were $57.91 \pm 7.68$ and $9.37 \pm 8.43$ years, respectively. Mean serum osteocalcin at baseline was $15.27 \pm 3.7 \mathrm{ng} / \mathrm{ml}$, which decreased significantly after 45 and 90 days of treatment with alendronate $(p=0.009$ and $p<0.001$, respectively). The levels of serum osteocalcin at days 45 and 90 in patients aged $<60$ and $\geq 60$ years were not significantly different. The levels of serum osteocalcin at days 45 and 90 in patients with a menopause duration of $<5$ and $\geq 5$ years were not significantly different. No significant difference was observed in serum osteocalcin levels at days 45 and 90 in patients with osteoporosis only in the femoral neck $(n=7)$, only in the lumbar spine $(n=20)$, and in both femoral neck and lumbar spine $(n=7)$. Measurement of serum osteocalcin is a less expensive, more available tool for monitoring the results of treatment in osteoporotic patients. It provides a practical suggestion about the effectiveness of treatment earlier than densitometry. As expected, osteocalcin levels decreased after treatment of osteoporosis.
\end{abstract}

Keywords: alendronate, osteocalcin, osteoporosis.

\section{Introduction}

Osteoporosis is the most prevalent skeletal disorder characterized by low bone mass, changes in the microscopic structure of bone, and increased bone fracture. Osteoporotic fractures most commonly happen in the wrist, hip, pelvis, and spine [1]. Osteoporosis is the second most common healthcare problem in the world after cardiovascular disease [2]. Osteoporosis mainly affects women after the menopause [1]. It has been suggested that menopause is associated with bone formation, resorption misbalance, and finally bone loss $[3,4]$. The prevalence of osteoporosis and its associated complications is increasing with life expectancy and may become an important health concern. Based on a meta-analysis, $17 \%$ and $35 \%$ of Iran's general population aged more than 30 years have osteoporosis and osteopenia, respectively [1].

Currently, there are many medications for the treatment of osteoporosis [5,6]. Alendronate, which is a second-generation bisphosphonate, has been used to treat osteoporosis for many years. The therapeutic effect of alendronate is through the direct inhibition of osteoclasts [7]. According to Black et al. [8], an increase of about $6 \%$ in bone mineral density (BMD) and a decrease of $50 \%$ in vertebral fracture rate were observed after a three-year treatment with alendronate [8]. Interestingly, the BMD increment was $32 \%$ more in the lumbar spine than in the hip, but the decrease in fracture risk at both areas was approximately the same [8].

Monitoring response to treatment is critical for the appropriate management of osteoporosis. DEXA is a valuable tool for the diagnosis and monitoring of response to treatment in osteoporosis; however, despite its importance, its value is limited because of the time it takes to assess the effect of treatment with DEXA [9]. To overcome this problem, the measuring of biochemical markers of bone formation and degradation has been suggested. Serum osteocalcin has emerged as a promising bone formation biomarker for the evaluation

* Corresponding Author: Aida Malek Mahdavi, E-mail: aidamalek@gmail.com, Tel: +98 4133369331

Received: 09 September 2017; Accepted: 12 September 2017 
of response to treatment in postmenopausal osteoporosis. Osteocalcin is produced by osteoblasts during bone formation [7,10], and it binds to the ccarboxyglutamic acid (Gla) residues because of its high affinity for calcium. This phenomenon promotes the absorption of calcium to the hydroxyapatite in bone matrix and leads to the mineralization of bone. Decreases in bone mineralization in osteoporotic postmenopausal females causes free osteocalcin to circulate in the blood [11]. Previous studies have indicated the prognostic value of osteocalcin for the evaluation of postmenopausal osteoporosis [12-15]. Jagtap et al. [11] reported a significant decrease in serum osteocalcin levels after alendronate treatment in women with postmenopausal osteoporosis. In another study on postmenopausal osteoporotic women [16], alendronate led to a significant decrease in serum osteocalcin levels compared to baseline and the placebo group. Moreover, Aonuma et al. [17], Sarioglu et al. [18], and Tascioglu et al. [19] indicated that treatment with alendronate led to a significant decrease in serum osteocalcin levels in postmenopausal osteoporotic women. The objective of the present study was to assess the effect of alendronate on serum osteocalcin levels in patients with postmenopausal osteoporosis.

\section{Materials and Methods}

In a before-and-after investigation, 34 postmenopausal osteoporotic women were recruited from the rheumatology clinic of AJA University of Medical Sciences (simple selection of samples based on number of most previous studies). Considering a confidence level of $95 \%$ and power of $80 \%$, the sample was determined with at least 25 cases. The sample size was increased to 34 cases after considering a possible dropout rate of $20 \%$. Inclusion criteria were having an age of 45-70 years and T-score values $\leq-2.5$ at the lumbar spine and/or neck of femur [20] measured by DEXA [(Bone mineral densitometry (BMD) for each patient was performed at baseline by dual-energy $\mathrm{x}$-ray absorptiometry (Hologic QDR Explorer machine; Hologic, Inc.)]. Exclusion criteria were contraindications for treatment with alendronate, having secondary causes of osteoporosis, using medications that affect bone metabolism, suffering from any metabolic bone diseases, and having a history of hormone replacement therapy. Informed consent was gained from all patients before entering the study. All patients received alendronate $10 \mathrm{mg} /$ day for 3 months (Osteofos 10mg-Cipla-India). Patients were visited at baseline, 45 and 90 days after therapy initiation. Five $\mathrm{mL}$ samples of blood were obtained after overnight fasting in each visit. Serum osteocalcin was measured with platinum enzyme-linked immunosorbent assay (ELISA) kits (BioSource hOST-EASIA Kit, BioSource Europe S.A. Rue de I'Industrie, 8, B-1400 Nivelles, Belgium). Serum calcium, phosphorus, and alkaline phosphatase (ALP) were determined by Auto-Analyzer (Abbott Park, Illinois, USA).

\section{Statistical analysis}

SPSS version 16.0 software (SPSS, Inc, Chicago, IL, USA) was used for statistical analysis. Normality was evaluated using the Kolmogorov-Smirnov test. Repeated measures analysis of variance was used to assess changes throughout the study, and assumptions of this analysis (e.g., homogeneity of variances and sphericity) were checked. Correlations were determined using Pearson's correlation coefficient, and $p<0.05$ was considered statistically significant.

\section{Results}

Thirty-four postmenopausal osteoporotic women entered this study, and all of them finished the study. Table 1 presents the demographic and clinical features of the participants.

Table 1. Baseline characteristics of the studied patients $(n=34)$

\begin{tabular}{lc}
\hline Characteristics & Mean \pm SD \\
\hline Age (years) & $57.91 \pm 7.7$ \\
Menopausal duration (years) & $9.37 \pm 8.4$ \\
T-score & \\
Femoral neck & $-2.15 \pm 0.8$ \\
Lumbar spine & $-2.78 \pm 0.7$ \\
Serum calcium (mg/dl) & $9.40 \pm 0.5$ \\
Serum phosphorous (mg/dl) & $3.77 \pm 0.5$ \\
Serum alkaline phosphatase (mg/dl) & $177.64 \pm 70.9$ \\
\hline
\end{tabular}

Figure 1 presents the serum osteocalcin levels of before and after treatment with alendronate. Mean serum osteocalcin at baseline was $15.27 \pm 3.7 \mathrm{ng} / \mathrm{ml}$ which decreased significantly after 45 and 90 days of treatment with alendronate $(p=0.009$ and $p<0.001$, respectively). In patients aged $<60$ and $\geq 60$ years, mean serum osteocalcin at baseline was $16.18 \pm 3.8$ $\mathrm{ng} / \mathrm{ml}$ and $13.33 \pm 2.95 \mathrm{ng} / \mathrm{ml}$, respectively (Fig. 2). Serum osteocalcin levels decreased significantly in both groups after 45 and 90 days of treatment with alendronate $(p<0.001$ and $p=0.001$, respectively), but the difference between the 2 groups was not significant (Fig. 2). 
Soroosh et al.

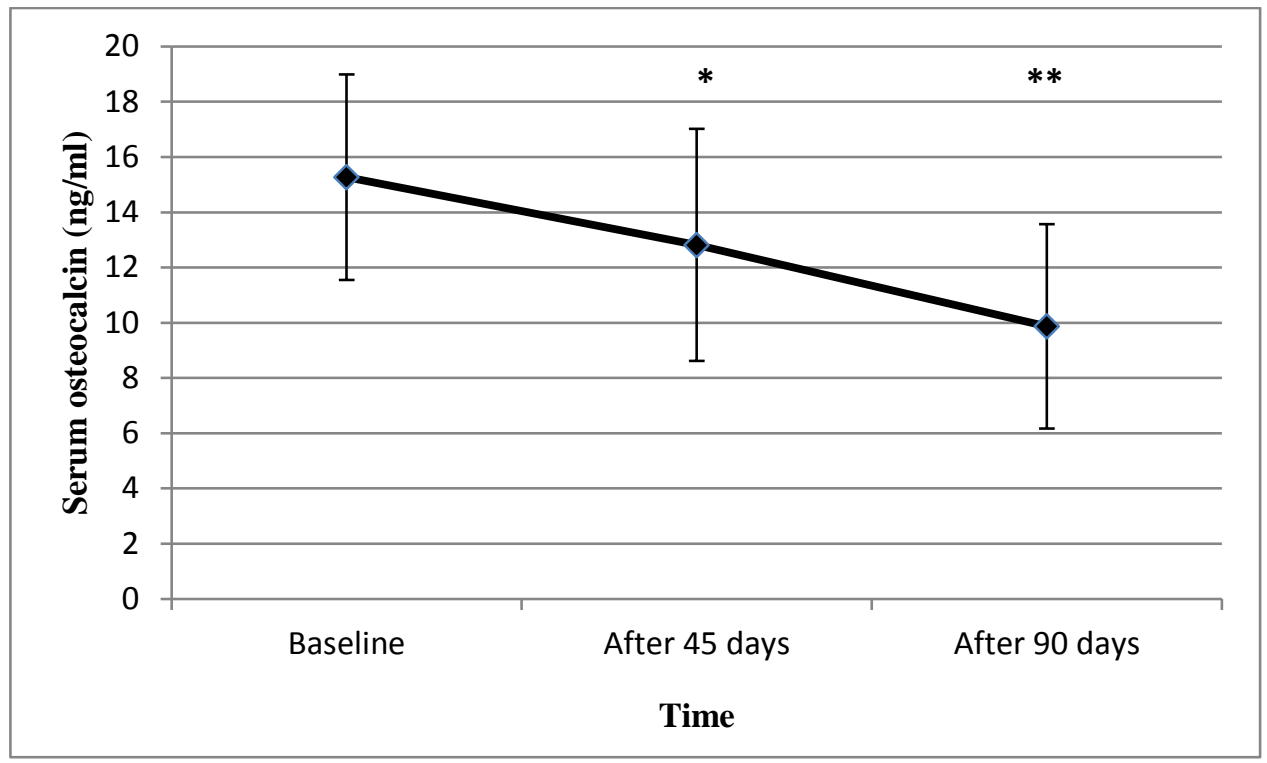

Fig. 1. Effect of alendronate treatment on serum osteocalcin levels $(n=34)$ $* p=0.009$ and $* * p<0.001$ based on the repeated-measures analysis of variance

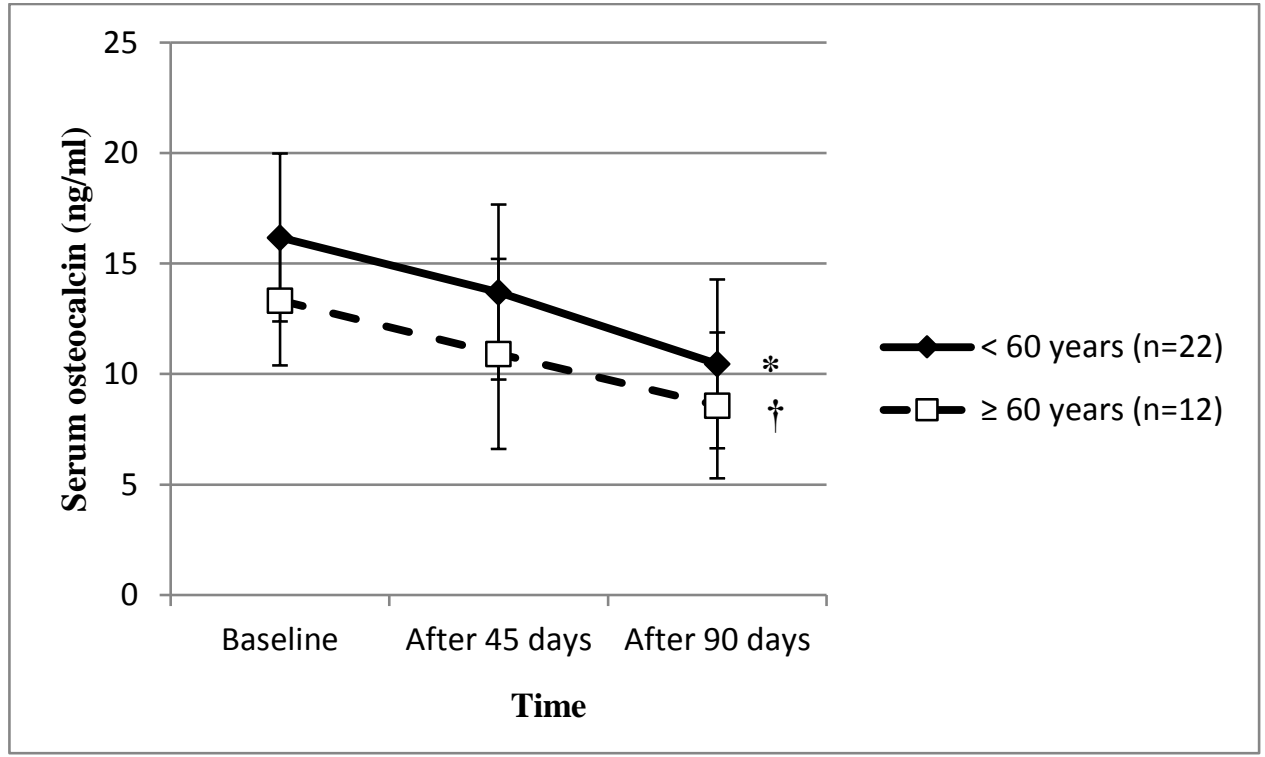

Fig. 2. Serum osteocalcin before and after treatment with alendronate in postmenopausal osteoporosis women with respect to the age group

$* p<0.001$ and $\uparrow p=0.001$ compared to baseline

Furthermore, mean serum osteocalcin levels were $15.53 \pm 4.5 \mathrm{ng} / \mathrm{ml}$ and $15.15 \pm 3.5 \mathrm{ng} / \mathrm{ml}$ in women with a menopause duration of $<5$ and $\geq 5$ years, respectively (Fig. 3). The decline in serum osteocalcin levels in both groups after 45 and 90 days of treatment with alendronate was significant $(p=0.002$ and $p<0.001$, respectively), but the difference between the 2 groups was not significant (Fig. 3). In patients with osteoporosis only in the femoral neck $(\mathrm{n}=7)$, only in the lumbar spine $(\mathrm{n}=20)$, and in both the femoral neck and the lumbar spine $(n=7)$, mean serum osteocalcin levels at baseline were $14.76 \pm 1.4 \mathrm{ng} / \mathrm{ml}, 16.35 \pm 4.3 \mathrm{ng} / \mathrm{ml}$, and $13.20 \pm 3.3 \mathrm{ng} / \mathrm{ml}$, respectively. The decrease in serum osteocalcin levels after 45 and 90 days of treatment in all 3 groups was significant $(p=0.007, p<0.001$, and $p=0.019$, respectively), but the difference between the groups was not significant (Fig. 4).

As indicated in Table 2, the mean baseline serum 
Postmenopausal osteoporotic women

osteocalcin levels did not correlate significantly with serum calcium, phosphorous, ALP, or BMD. Furthermore, correlations between changes in serum osteocalcin level and serum calcium, phosphorous, and ALP were not significant.

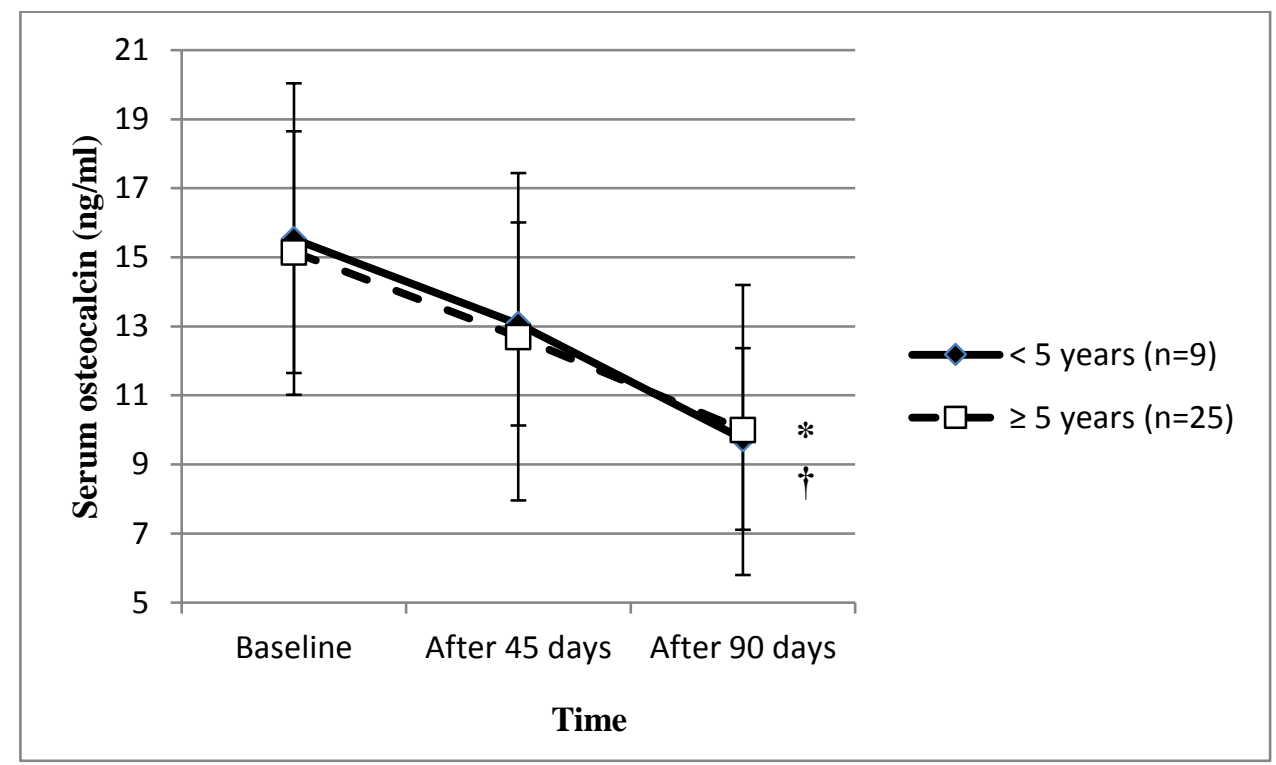

Fig. 3. Serum osteocalcin before and after treatment with alendronate in postmenopausal osteoporosis women with respect to the menopausal duration

${ }^{*} p=0.002$ and $\dagger p<0.001$ compared to baseline

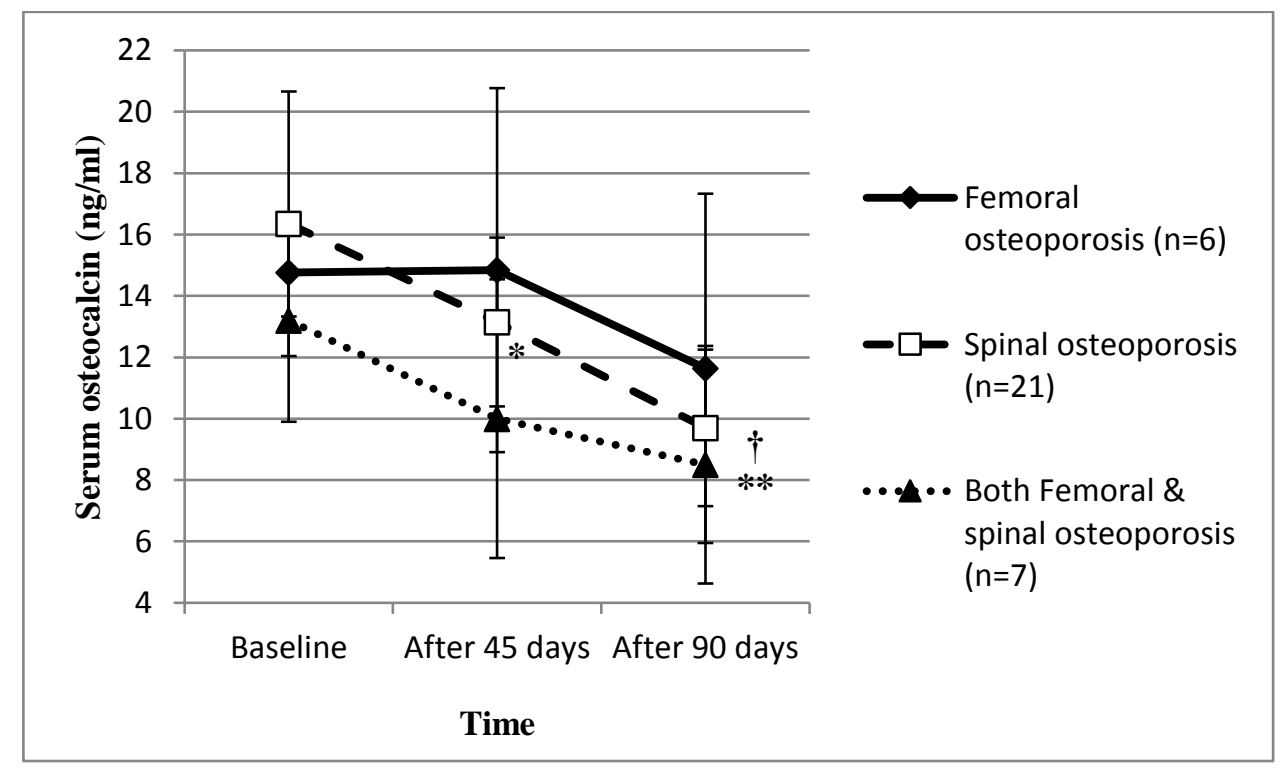

Fig. 4. Serum osteocalcin before and after treatment with alendronate in postmenopausal osteoporosis women with respect to the osteoporosis

${ }^{*} p=0.007, \dagger p<0.001$ and ${ }^{* *} p=0.019$ compared to baseline 
Table 2. Correlation between baseline levels of serum osteocalcin with serum calcium, phosphorous, alkaline phosphatase and BMD $(n=34)$

\begin{tabular}{lcc}
\hline & \multicolumn{2}{c}{ Osteocalcin $(\mathbf{n g} / \mathbf{m l})$} \\
\cline { 2 - 3 } & $\mathbf{r}$ & $\boldsymbol{P}^{*}$ \\
\hline Calcium $(\mathrm{mg} / \mathrm{dl})$ & -0.038 & 0.864 \\
Phosphorous $(\mathrm{mg} / \mathrm{dl})$ & 0.012 & 0.955 \\
Alkaline phosphatase & 0.260 & 0.242 \\
$(\mathrm{mg} / \mathrm{dl})$ & & \\
BMD $\left(\mathrm{g} / \mathrm{cm}^{2}\right)$ & 0.175 & 0.321 \\
Femoral neck & 0.111 & 0.532 \\
Lumbar spine & & \\
* Pearson's correlation coefficient
\end{tabular}

\section{Discussion}

Based on the results of the current study, three months of treatment with alendronate was effective in reducing serum osteocalcin levels in postmenopausal osteoporotic women. Mean baseline serum osteocalcin levels did not correlate significantly with serum calcium, phosphorous, ALP, or BMD. Furthermore, correlations between changes in serum osteocalcin level and serum calcium, phosphorous, and ALP after 90 days of alendronate treatment were not significant. No correlation was observed between age, menopause duration, osteoporosis site, and changes in serum osteocalcin levels during treatment with alendronate.

Jagtap et al. [11] reported a significant decrease in serum osteocalcin levels after treatment with alendronate (70 mg/week for 3 months) in women with postmenopausal osteoporosis. In another study on postmenopausal osteoporotic women [16], $20 \mathrm{mg}$ alendronate once a week for 3 months led to a significant decrease in serum osteocalcin levels compared to baseline and the placebo group. Consistent with the current study, Aonuma et al. [17] indicated that treatment with alendronate $5 \mathrm{mg}$ /day for durations of both $<$ and $\geq 6$ months led to a significant decrease in serum osteocalcin levels in postmenopausal osteoporotic women. Moreover, Hirao et al. [21] demonstrated that alendronate $5 \mathrm{mg} /$ day for 12 months decreased serum undercarboxylated osteocalcin significantly. In Sarioglu et al. [18] and Tascioglu et al. [19], treatment with alendronate $(70 \mathrm{mg} /$ week for 12 months and $10 \mathrm{mg} /$ day for 24 months, respectively) led to a significant reduction in serum osteocalcin levels in postmenopausal osteoporotic women. Results of the current study were also consistent with those of Johannes et al. [22], Ones et al. [23], Sambrook et al. [24], and Ivaska et al. [25]. Consistent with the current study, Aonuma et al. [17] stated no significant correlation between BMD and changes in serum osteocalcin levels after treatment with alendronate. Furthermore, Choi et al. [16] did not show a significant correlation between baseline lumbar spine BMD and changes in bone turnover markers after treatment with alendronate. In another study by Min et al. [26], baseline osteocalcin concentrations as well as changes after 3 and 6 months of therapy did not correlate with BMD after the study. It has been indicated that bone turnover markers may be useful when BMD changes are too small [27]. During antiresorptive therapy, short-term changes in bone turnover markers are related to longterm changes in BMD [28-30]. Moreover, greater reductions in bone turnover immediately after the initiation of treatment are associated with fewer bone fractures in the future $[31,32]$. It has been indicated that alendronate regulates ephrinB1 gene expression in osteoclasts, which interacts with EphB1 or B3 receptors on osteoblasts to inhibit osteoblast function; therefore, it suppresses osteoblast differentiation indirectly. Furthermore, alendronate may affect osteoclast precursors, which then act on osteoblast precursors in bone marrow cells through ephrinB1-EphB interactions [33].

In the present research, the sample size was small and the duration of treatment with alendronate was short; these could be considered as limitations of the study. Furthermore, fracture risk was not evaluated.

\section{Conclusion}

In conclusion, short-term prospective determinations of biochemical markers of bone turnover can be used in assessing early response to therapy, monitoring alendronate treatment, and predicting long-term change in bone mass. Verification of the study data by largescaled longitudinal studies and the use of other bone formations and resorption markers plus confirmation of treatment response with BMD in one or two years will lead to better utilization of selected biochemical markers to guide practice for postmenopausal women with osteoporosis.

\section{Conflicts of interest}

The authors declare no conflict of interest.

\section{Acknowledgments}

The authors wish to thank Dr. Sousan Soroush and Dr. Sirous Djafarian for their cooperation in this research. We also thank all the patients for their participation in this study. 
Postmenopausal osteoporotic women

\section{Source of funding}

This research was financially supported by AJA

University of Medical Sciences.

\section{References}

1. Doosti Irani A, Poorolajal J, Khalilian A, Esmailnasab $\mathrm{N}$ Cheraghi Z. Prevalence of osteoporosis in Iran: A metaanalysis. J Res Med Sci 2013; 18(9): 759-66.

2. Moyad MA. Preventing male osteoporosis: prevalence, risks, diagnosis and imaging tests. Urol Clin North Am 2004; 31(2): 32130. doi: http://dx.doi.org/10.1016/ j.ucl.2004.01.008.

3. Sambrook P, Cooper C. Osteoporosis. Lancet 2006; 367 : 2010-18. doi: 10.1016/S01406736(06)68891-0.

4. Dogan E, Posaci C. Monitoring hormone replacement therapy by biochemical marker of bone metabolism in menopausal women. Post Graduate Med J 2002; 78: 727-31. doi: org/10.1136/pmj.78.926.727.

5. Iwamoto J, Takeda $\mathrm{T}$, Sato $\mathrm{Y}$. Efficacy and safety of alendronate and risedronate for postmenopausal osteoporosis. Curr Med Res Opin 2006; 22(5): 519-28. doi: 10.1185/0300799 06X100276.

6. Iwamoto J, Takeda T, Sato Y. Effects of antifracture drugs in postmenopausal, male and glucocorticoid-induced osteoporosis-usefulness of alendronate and risedronate. Expert Opin Pharmacother 2007; 8(16): 2743-56. doi: 10.1517/14656566.8.16.2743.

7. Civitelli R, Armamento-Villareal R, Napoli N. Bone turnover markers: understanding their value in clinical trials and clinical practice. Osteoporosis Int 2009; (20):853-1. doi: 10.1007/s00198009-0838-9.

8. Black DM, Cummings SR, Karpf DB, Cauley JA, Thompson DE, Nevitt MC, et al. Randomised trial of effect of alendronate on risk of fracture in women with existing vertebral fractures. Fracture Intervention Trial Research Group. Lancet 1996; 348(9041): 1535-41, doi: 10.1016/s0140-6736(96)07088-2.
9. Ghazi M, Mounach A, Nouijai A, Ghozlani I, Bennani L, Achemlal $\mathrm{L}$, et al. Performance of the osteoporosis risk assessment tool in Moroccan men. Clin Rheumatol 2007; 26(12): 203741. doi: 10.1007/s10067-0070611-4.

10. Hamdi RA. Evaluation of Serum Osteocalcin level in Iraqi Postmenopausal women with primary osteoporosis. J Fac Med Baghdad 2013; 55(2): 166-9.

11. Jagtap VR, Ganu JV, Nagane NS. BMD and serum intact osteocalcin in postmenopausal osteoporosis women. Ind J Clin Biochem 2013; 26(1): 70-3. doi: 10.1007/s12291-010-0074-2.

12. Pino JD, Gomez EM, Rodriguez MM, Sosa CL, Cordero M, Lanchares JL, Talavera JRG. Influence of sex, age and menopause in serum osteocalcin (BGP) levels. J Mol Med 1991; 69(24): 1135-8, doi: 10.1007/ bf01815430.

13. Verit FF, Yazgan P, Geyikli C, Zer Y, Celik A. Diagnostic value of TRAP $5 \mathrm{~b}$ activity in postmenopausal osteoporosis. $\boldsymbol{J}$ Turkish-German Gynecol Assoc 2006; 7(2): 120-4

14. Cabrera CD, Henriquez MS, Traba ML, Villafane EA, Piedra DL. Biochemical markers of bone formation in the study of postmenopausal osteoporosis. Osteoporos Int 1998; 8(2): 147 51. doi:10.1138/20070266.

15. Rosenquist $\mathrm{C}$, Qvist $\mathrm{P}, \mathrm{Bjarnason}$ $\mathrm{N}$, Christiansen C. Measurement of a more stable region of osteocalcin in serum by ELISA with two monoclonal antibodies. Clin Chem 1995; 41(10): 143945.

16. Choi HJ, Im JA, Kim SH. Changes in bone markers after once-weekly low-dose alendronate in postmenopausal women with moderate bone loss. Maturitas 2008; 60: 170-6. doi: org/10.1016/j.maturitas.2008.05.0 03.

17. Aonuma $\mathrm{H}$, Miyakoshi N, Hongo M, Kasukawa Y, Shimada Y.
Low serum levels of
undercarboxylated osteocalcin in
postmenopausal osteoporotic
women receiving an inhibitor of
bone resorption. Tohoku $\boldsymbol{J}$ Exp
Med 2009; 218(3): 201-5, doi:
10.1620/tjem.218.201.

18. Sarioglu M, Tuzun C, Unlu Z, Tikiz C, Taneli F, Uyanik BS. Comparison of the effects of alendronate and risedronate on bone mineral density and bone turnover markers in postmenopausal osteoporosis. Rheumatol Int 2006; 26: 195 200. doi: 10.1007/s00296-0040544-z.

19. Tascioglu F, Colak O, Armagan $\mathrm{O}$, Alatas $\mathrm{O}$, Oner $\mathrm{C}$. The treatment of osteoporosis in patients with rheumatoid arthritis receiving glucocorticoids: a comparison of alendronate and intranasal salmon calcitonin. Rheumatol Int 2005; 26: 21-9. doi: 10.1007/s00296-004-0496-3.

20. World Health Organization. Assessment of fracture risk and its application to screening for postmenopausal osteoporosis. WHO Technical Report Series 843, Geneva (1994).

21. Hirao M, Hashimoto J, Ando W, Ono T, Yoshikawa H. Response of serum carboxylated and undercarboxylated osteocalcin to alendronate monotherapy and combined therapy with vitamin $\mathrm{K} 2$ in postmenopausal women. $\boldsymbol{J}$ Bone Miner Metab 2008; 26: 260-4. doi: 10.1007/s00774-0070823-3.

22. Johannes WG, Pet PMM, Ron NJ, Lems WF, Roland FJ, Ann MH, Ale A, Erik B, Lorenz $\mathrm{CH}$, George AWB, Ben ACD. Prevention of glucocorticoid induced osteoporosis with alendronate or alfa calcidiol: relations of change in bone mineral density, bone markers and calcium homeostasis. $\boldsymbol{J}$ Rheumatol 2007; 34: 1051-7.

23. Ones K, Schacht E, Dukas L, Caglar N. Effects of combined 
treatment with alendronate and alfacalcidol on bone mineral density and bone turnover in postmenopausal osteoporosis: a two years, randomized, multiarm, controlled trial. Int J Epidemiol 2007; 4(4): 1-9, doi: 10.5580/ 1523 .

24. Sambrook PN, Kotowicz M, Nash $\mathrm{P}$, Styles $\mathrm{CB}$, Naganathan $\mathrm{V}$, Henderson -Briffa KN, Eisman A, Nicholson GC. Prevention and treatment of glucocoriticoidinduced osteoporosis: a comparison of calcitriol, vitamin $\mathrm{D}$ plus calcium, and alendronate plus calcium. $J$ Bone Miner Res 2003; 18(5): 919-24. doi: 10.1359/jbmr.2003.18.5.919.

25. Ivaska KK, Pettersson K, Nenonen A, Uusi-Rasi K, Heinonen A, Kannus P, Vaananen HK. Urinary Osteocalcin Is a Useful Marker for Monitoring the Effect of Alendronate Therapy. Clin Chem 2005; 51(12): 2362-5. doi: $\quad 10.1373 /$ clinchem.2005. 055541.

26. Min YK, Lee DY, Choi SJ, Kim JH, Choi DS, Yoon BK. Effects of adding alendronate to ongoing hormone therapy on bone mineral density in postmenopausal Korean women: a randomized, double-blind, placebo-controlled clinical trial. Menopause 2013; 20(7): 761-6. doi: 10.1097/GME. 0b013e31827b24af

27. Looker AC, Bauer DC, Chesnut CH III, Gundberg CM, Hochberg MC, Klee G, et al. Clinical use of biochemical markers of bone remodeling: current status and future directions. Osteoporos Int 2000; 11(6): 467-80, doi: $10.1007 / \mathrm{s} 001980070088$

28. Ravn P, Clemmesen B, Christiansen C. Biochemical markers can predict the response in bone mass during alendronate treatment in early postmenopausal women. Alendronate Osteoporosis Prevention Study Group. Bone 1999; 24(3): 23744, doi: 10.1016/s8756-3282(98) 00183-5.

29. Ravn P, Thompson DE, Ross PD, Christiansen C. Biochemical markers for prediction of 4-year response in bone mass during bisphosphonate treatment for prevention of postmenopausal osteoporosis. Bone 2003; 33(1): 150-8, doi: 10.1016/s87563282(03)00168-6.

30. Greenspan SL, Resnick NM, Parker RA. Early changes in biochemical markers of bone turnover are associated with longterm changes in bone mineral density in elderly women on alendronate, hormone replacement therapy, or combination therapy: a threeyear, double-blind, placebocontrolled, randomized clinical trial. J Clin Endocrinol Metab 2005; 90: 2762-7. doi: 10.1210/ jc.2004-1091.

31. Bauer DC, Black DM, Garnero P, Hochberg M, Ott S, Orloff J, et al. Change in bone turnover and hip, non-spine, and vertebral fracture in alendronate treated women: the fracture intervention trial. J Bone Miner Res 2004; 19: 1250-8. doi: 10.1359/JBMR. 040512.

32. Eastell R, Barton I, Hannon RA, Chines A, Garnero P, Delmas PD. Relationship of early changes in bone resorption to the reduction in fracture risk with risedronate. $\boldsymbol{J}$ Bone Miner Res 2003; 18: 10516. doi: 10.1359/jbmr.2003.18.6. 1051.

33. Shimizu E, Tamasi J, Partridge NC. Alendronate Affects Osteoblast Functions by Crosstalk through EphrinB1-EphB. J Dent Res 2012; 91(3): 268-274. doi: $10.1177 / 0022034511432170$. 